\title{
Correction to: Date palm waste-derived biochar composites with silica and zeolite: synthesis, characterization and implication for carbon stability and recalcitrant potential
}

\author{
Munir Ahmad • Mahtab Ahmad • Adel R. A. Usman • Abdullah S. Al-Faraj • \\ Adel Abduljabbar $\cdot$ Yong Sik Ok • Mohammad I. Al-Wabel
}

Published online: 27 December 2017

(C) Springer Science+Business Media B.V., part of Springer Nature 2017

Correction to: Environ Geochem Health https://doi.org/10.1007/s10653-017-9947-0

Unfortunately, in the original publication of the article, Prof. Yong Sik Ok's affiliation was incorrectly published. The author's affiliation is as follows.

The original article can be found online at https:// doi.org/10.1007/s10653-017-9947-0.

M. Ahmad · M. Ahmad · A. R. A. Usman ·

A. S. Al-Faraj · M. I. Al-Wabel ( $\square)$

Soil Sciences Department, College of Food and Agricultural Sciences, King Saud University,

P.O. Box 2460, Riyadh 11451, Kingdom of Saudi Arabia

e-mail: malwabel@ksu.edu.sa

M. Ahmad

Department of Environmental Sciences, Faculty of

Biological Sciences, Quaid-I-Azam University,

Islamabad 45320, Pakistan

A. R. A. Usman

Department of Soils and Water, Faculty of Agriculture,

Assiut University, Assiut 71526, Egypt

A. Abduljabbar

Industrial Psychology, College of Education, King Saud

University, Riyadh, Saudi Arabia
1. Kangwon National University, Chuncheon 24341, Republic of Korea

2. O-Jeong Eco-Resilience Institute (OJERI), Division of Environmental Science and Ecological Engineering, Korea University, Seoul, Republic of Korea

Y. S. Ok

Korea Biochar Research Center and Department of Biological Environment, Kangwon National University, Chuncheon 200-701, Republic of Korea

Y. S. Ok

O-Jeong Eco-Resilience Institute (OJERI), Division of Environmental Science and Ecological Engineering,

Korea University, Seoul, Republic of Korea e-mail: yongsikok@korea.ac.kr 